\title{
Stigma and Exclusion in Cross-Cultural Contexts
}

\author{
Annie Pohlman, Sol Rojas-Lizana and Maryam Jamarani, University of \\ Queensland, guest editors
}

Discriminatory and marginalising discourses affect the cultural and social realities of people in all human societies. Across time and place, these discourses manifest in numerous tangible and intangible ways, creating stigma and forms of exclusion by means particular to their cultural, historical, political and social contexts. These discourses also manifest in varying degrees of harm; from verbal abuse and behavioural forms of exclusion, to physical abuse and neglect, and exclusionary practices at institutional, legal and regulatory levels. Such forms of stigma cause direct physical and mental harm and other forms of persecution.

The papers in this special issue arise from a one-day symposium held at the University of Queensland in February 2013. The symposium, 'Stigma and Exclusion in CrossCultural Contexts,' brought together researchers and community-based practitioners from across Australia and overseas to explore marginalisation, discriminatory discourses and stigma in a wide range of historical and cross-cultural settings. By critically engaging with experiences of social, political and cultural exclusion and marginalisation in different contexts, we aimed to elucidate how discourses of stigma are created, contested and negotiated in cross-cultural settings. We also aimed to explore stigmatisation in its lived realities: as discourses of exclusion; as the fleshy

PORTAL Journal of Multidisciplinary International Studies, vol. 11, no. 1, January 2014.

Stigma and Exclusion in Cross-Cultural Contexts Special Issue, guest edited by Annie Pohlman, Sol Rojas-Lizana and Maryam Jamarani. 
reality of discrimination in social worlds; as part of the life narratives of individuals and groups; and as discourses of agency and counter-discourses in responding to stigma.

Following the symposium, we invited speakers to submit articles that reflected on the special issue's theme of stigma in cross-cultural contexts. The papers assembled here are the result of that process and reflect a wide range of disciplinary stances, areas of geographical focus, historical contexts and thematic approaches to the study of stigma and exclusionary practices around the world. Amongst the contributions, authors examine stigma and experiences of exclusion in Australia, Indonesia, France, Iran, Romania, Czech Republic, Slovakia, Rwanda and Argentina. While all the papers examine stigma, exclusion and discrimination, individual contributions approach this topic from particular areas of concern. The contributions range from analyses of discrimination based on race, sexual identity, gender and religion, to the stigma faced by people with mental illness, to more extreme processes of marginalisation which result in dehumanisation and incitement to mass violence. The disciplinary approaches to this area of research on stigma are also widespread: amongst the contributors there are historians, psychologists, political scientists, Asian studies specialists, linguists, critical discourse analysis researchers and cultural theorists. Taken together, these contributions address some of the many complex realities of stigma and exclusion, elucidating the contextual aspects and discursive functions of discriminatory discourses around the world.

The contributions have been organised by topic. First, stigma and exclusion in the area of gender and sexuality are explored in two papers, Bronwyn Winter's contribution on gay marriage and Sol Rojas-Lizana's examination of LGBTIQ discrimination. Winter looks at the challenges and forms of exclusion that could result from the legalisation of gay marriage, calling our attention to the consequences of normalising ideas of 'the family' in Western neo-liberal societies. Since families are at the base of social fabric, to be married — for both heterosexuals and homosexuals-means to conform better with what it is considered to be fully human, as set down in the 1948 Universal Declaration of Human Rights. Gay marriage has become a major transnational gay rights issue and a key marker of gay citizenship, to the extent that it is considered self-evident that its legalisation represents progress. Yet it is becoming apparent that this 'progress' is concurrent with other forms of exclusion, of which the differences in status between the 
married and the unmarried have attracted the most attention to date. The article reflects on how three states (Argentina, France and Australia) have used gay marriage to improve their image in terms of their social-justice credentials while ignoring other social justice issues, including some LGBTIQ rights. The author argues that gay marriage is a convenient liberal smokescreen that, in reassuring progressive elites, deflects the focus from neoliberal, so-called security and other discriminatory measures taken by states that may be far more worrying for homosexuals (and many others) in the longer term.

In her contribution Rojas-Lizana builds a taxonomy of discrimination for a Brisbanebased LGBTIQ self-identifying group based on their own accounts of discrimination. The author identifies verbal and behavioural forms of discrimination, elucidates the forms of verbal discrimination and offers an analysis of the discourse used in the construction of the experiences and of the effects reported. The results show that verbal discrimination is an overt phenomenon and that participants are stressed by the everpresent possibility of facing it. Verbal discrimination is mainly triggered by a perceived transgression against the normalised standards of people's behaviour, movements and appearance in a heterosexist society. Rojas-Lizana presents three subtypes: name-calling, abuse and remarks, which are described through the analysis of keywords, effects and expressions (such as 'faggot,' 'gay,' 'dyke,' 'queer,' the pronoun 'it,' religious comments and other remarks). The contribution reveals the powerful effects of verbal discrimination against people who identify as LGBTIQ.

Fearing rejection by family and/or society and receiving the stigmatised 'mental illness' label can result in inhibiting individuals suffering from various degrees of mental illness from seeking help. Jen Lee Teh and her colleagues present the results of their study on the interplay and correlation between two types of personal stigma in people with mental illness and their willingness to communicate for help. Making a distinction between self-stigma (internalised negative beliefs) and perceived stigma (anticipated or expected external sources of stigma), their study focuses on anticipated stigma and its connection with help seeking behaviours. The authors examined the online survey results of 72 participants who had experienced mental illness at some stage in their life, with follow up interviews with 17 of them. All the participants resided in Australia but came from a variety of ethnic backgrounds. The authors’ results highlight the 
importance of building resilience as well as cultural-specific strategies for overcoming persistent mental illness stigma.

In her study of the literary representation of Iranian men in diasporic Iranian literature, Sanaz Fotouhi analyses the causes and consequences of the stigmatised image of the Middle Eastern (particularly Iranian) man in the West. Middle Eastern Muslim men have been historically subjected to stereotypical representations in the West and, following the 1979 Islamic revolution and the American hostage crisis in Iran, Iranian men and masculinity have become hypervisible as aggressive and religiously fanatic. Moreover, in the past decade memoirs and fictional accounts written in English by Iranian women have reinforced this hypervisible and violent image of Iranian men. The author first examines the self-Orientalising discourses presented by Iranian women authors in their autobiographical novels, whereby they rely on stories of repressed women whose basic freedoms are impinged upon by men in the patriarchal society. Fotouhi then moves to examine narratives written by Iranian men in the West and shows how the stigmatised image of Iranian men in the West has impeded the integration of diasporic Iranian men in their host societies.

Zane Goebal's contribution to this special issue offers an examination of neighbourhood talk with a particular focus on negative stereotypes of 'Chineseness' in Indonesia and the stigmatising of an individual within a small community. By providing an in-depth analysis of conversations during two meetings of men in a local community in Central Java, Goebel delves into the complex processes by which individuals and groups create stigmatising discourses through positioning certain individuals as deviant. Drawing on constructs of and enduring stereotypes about Indonesians of Chinese ancestry in Indonesia, the men in these meetings used these stereotypes in their own formulations to stigmatise an individual within their community based on his associated negative 'Chinese' traits and behaviours. By revealing these micro-level processes of stigmatisation, Goebel's analysis exposes the progression by which the discourse of individuals and communities can function to exclude, sanction and marginalise others.

The final four contributions of this special issue deal with the relationship between exclusionary discourses, stigma and mass atrocities. The essays by Narelle Fletcher, Annie Pohlman and Emma Townsend examine the relationship between discriminatory discourse and incitement to genocide and mass atrocity crimes, while Jill Stockwell's 
paper reflects on stigma and memorial cultures in the transitional justice context of postdictatorship Argentina. The first two contributions on this theme examine incitement to genocidal violence in specific historical contexts: Fletcher in regard to the genocide in Rwanda in 1994; and Pohlman in the context of the genocidal massacres against those associated with the Indonesian Communist Party (PKI) following an abortive coup on 1 October 1965. In both cases, the authors demonstrate how incitement played a crucial function in mobilising parts of the population in these countries to take part in mass atrocities.

In Fletcher's article, she offers a close reading of a particularly infamous speech made by Léon Mugesera some eighteen months prior to the outbreak of the genocide in Rwanda on 6 April 1994. This speech was made in a small town and delivered to only approximately 1,000 attendees but it was also recorded and rebroadcast in the lead-up to the killings. Known for its virulent genocidal discourse, this speech became infamous for offering what Fletcher describes as a plan for implementing the massacres. After the genocide, Mugesera fled to Canada as a refugee. After a decade of judicial proceedings in Canada, Mugesera was deported to Rwanda in 2012 to face prosecution for incitement to genocide. What Fletcher offers is more than a description of this speech and its contents. Rather, she reflects carefully on how this speech was interpreted and contested during the Canadian judicial proceedings, highlighting how Mugesera refuted the claim of genocidal incitement by obscuring the meaning of his words. In her analysis, Fletcher examines the French translations of the original speech made in Kinyarwanda and reveals the often insidious forms of genocidal discourse that were, in some cases, purposefully obfuscated in the translations for the Canadian court. By doing so, she brings focus to how discourse that is used to incite mass violence must be carefully interpreted, taking into account crucial linguistic and sociocultural factors.

In her article, Pohlman analyses genocidal incitement in the historical context of mid1960s Indonesia. She begins by examining the Indonesian massacres of 1965-1966 as genocidal violence and reflecting on the definitional debates over what constitutes genocide as per the UN Convention on the Prevention and Punishment of the Crime of Genocide. Pohlman then focuses on the Indonesian military's mass propaganda campaign following the coup in October 1965 that incited the massacres of an estimated 500,000 'suspected Communists.' She also highlights some recent developments in 
international criminal law on incitement to genocide and compares these with the possible culpability of those who created the Indonesian military's campaign. Pohlman thus underlines the importance of examining extreme forms of dehumanisation and stigmatisation that lead to mass atrocities.

Emma Townsend also examines extreme forms of dehumanising discourse, taking as her focus hate speech against Roma in contemporary Europe. By analysing recent examples of hate speech and other severe discourses of stigmatisation against Roma across a number of European contexts, Townsend questions whether this discourse should be considered genocidal. In the first part of her essay, she tracks historical trends in anti-Roma discourse in Europe, providing the important context for contemporary formations of this hate speech. She then argues that serious persecution of Roma has continued in the post-War period, pointing to several examples of severe forms of state repression against Roma communities in the latter half of the Twentieth century. In the main part of her article, Townsend turns her attention to Twenty-first century examples of anti-Roma discourse and persecution, particularly in the Czech Republic, Slovakia and France. Townsend provides a continuum of this discourse, which begins in hate speech, progresses to genocidal discourse and culminates in incitement.

The final article in this special issue is Jill Stockwell's exploration of women's memories and competing political perspectives in contemporary Argentina. Between 1976 and 1983, Argentina's right-wing military dictatorship persecuted those on the political Left, the most well-known form of this persecution being the kidnap, torture and execution of activists, or the desaparecidos (the disappeared). Prior to the take-over of the government in 1976, however, Leftist and Rightist forces had been involved in violent struggles for power, including armed guerrilla violence by Leftists. Now, nearing four decades since the end of the dictatorship, Argentina remains deeply divided, with competing claims about how the regime and its victims should be remembered continuing to dominate contemporary political debates. Stockwell interviewed women who lost loved ones from both the Left (during the dictatorship) and from the Right (during the guerrilla armed actions prior to the 1976 coup). By exploring these women's testimonies, and by drawing on understandings of how deep memory and affect are crucial to the formation and continuation of memorial cultures on both sides, Stockwell 
tries to find ways to move beyond the stigma and political and ideological contestations which divide the two groups of women.

The articles in this special issue represent the work of a diverse group of practitioners and researchers from an array of disciplinary backgrounds. Yet each focuses on the discourses of stigma, which range from the everyday speech of exclusion, through marginalising discourse in communities and states, to discourse inciting harm against persecuted groups. The different forms of stigma examined in this special issue span different historical, political and geographical contexts, the resultant analyses revealing complex stories about how individuals and groups are excluded from their families, communities and even nations. Some of the contributors issue a call for intervention, to create better and more suitable strategies to repair the harm of stigma or to prevent stigma. Other contributors ask us to consider the complex realities of those who live with stigma. And others demand that justice be sought for those who have been stigmatised and oppressed. By considering stigma in some of its many manifestations and as a fundamental form of harm that people can do to others, the contributions to this special issue require us to explore more widely and more deeply the multifaceted realities of marginalisation and exclusion. 